\title{
Who is discriminated most in the EU? An analysis of the Covid-19 compensation fund
}

\author{
Alfred Greiner
}

Benjamin Owusu 


\title{
Who is discriminated most in the EU? An analysis of the Covid-19 compensation fund
}

\author{
Alfred Greiner \\ Benjamin Owusu*
}

\begin{abstract}
The European Union has set up a fund in order to compensate countries for damages resulting from Covid-19 that hit the economies in an asymmetric way. We argue that payments should be based only on relative damages, expressed as losses relative to GDP, and any distribution mechanism implying that damages in the countries are treated differently is discriminatory. Hence, we compute the compensation payments if the resources of the fund are spent according to the relative loss in GDP. Finally, we compare the compensations relative to the losses in GDP, resulting from the application of that principle, with those obtained by distributing the funds as suggested by the Council of the European Union. Our results provide evidence of discrimination by the EU Covid-19 compensation package.
\end{abstract}

JEL: H12, H84

Keywords: Covid-19, European Union, transfers, discrimination

${ }^{*}$ Department of Business Administration and Economics, Bielefeld University, P.O. Box 100131, 33501 Bielefeld, Germany, e-mail: agreiner@uni-bielefeld.de, benjamin.owusu@uni-bielefeld.de 


\section{Introduction}

The European Union (EU) has decided to set up a fund in order to compensate the economies of the EU for damages that resulted from the Covid-19 pandemic that hit the countries asymmetrically. ${ }^{1}$ According to the Council of the EU about 312 billion euros in prices of 2018 are to be distributed as compensation payments that need not be paid back. The suggested distribution mechanism states that $70 \%$ of the fund is distributed according to the average unemployment rate of a country from 2015-2019 relative to the average unemployment rate in the EU over that period multiplied by the inverse of the country's per capita GDP relative to the EU average GDP per capita in 2019 multiplied by the economy's population relative to the total population in the EU. The other $30 \%$ are distributed according to the relative loss of GDP in a country between 2020 and 2019 and between 2021 and 2019, relative to the EU average loss respectively, again weighted by the inverse level of per capita GDP and by the population relative to the EU average in 2019. Further, there are upper bounds with respect to the criteria, for details see Council of the European Union (2020), p. 46-49.

Since the compensation fund has been created in order to compensate the damages resulting from the Covid-19 pandemic, the relative loss in GDP should be the only criterion according to which the payments are distributed. When resources are distributed according to criteria unrelated to that exogenous shock, such as the unemployment rate before the shock, this implies that the damages in the countries are treated unequally, i.e. the relative loss of 1 euro in country $\mathrm{A}$ is treated differently than that of 1 euro in country B. Hence, equal situations are treated unequally implying (horizontal) inequality and, thus, discrimination of citizens in the EU.

When allocating the resources across EU Member States, one possible criteria could be to resort to sacrifice theories (see e.g. Lenzi, 2008) to determine the allocation of the payments. Usually, sacrifice theories are resorted to in order to implement the ability-topay principle that is used as a justification for income taxation. The concept of the same absolute sacrifice requires that each individual makes the same sacrifice in terms of the same reduction of its utility as a result of the tax. The same relative sacrifice is given

\footnotetext{
${ }^{1}$ The official name of that fund is Recovery and Resilience Facility. We call it compensation fund.
} 
when the decline in utility relative to utility before taxation is the same for all individuals. With this concept, individuals with a higher initial level of utility bear a higher reduction of their utility in absolute values.

In Greiner and Owusu (2020) it has been shown how these two sacrifice concepts can be resorted to in order to determine the compensation payments out of the Covid-19 compensation fund, where the GDP in the economies has been adjusted by a purchasing power price index. There, both the same absolute and the same relative sacrifice principles have been used to determine the payments for compensation funds comprising 750 and 500 billion euros, respectively. However, it must be stated that this procedure represents an extreme form of inter-governmental assistance because it implies that the damages after compensation are equal in each country, either in absolute values per capita or relative to GDP. Further, it turned out that for low values of the compensation fund, economies with relatively small damages do not get compensation, but, rather have to contribute to the fund. For example, the same absolute sacrifice principle, applied to a fund of 500 billion euros, implies that some countries do not get any compensation, but, have to pay to the fund since their per capita damage is lower than the same absolute loss per capita in the EU.

Another possibility to determine the compensation payments is to make them proportional to the relative losses in GDP caused by Covid-19, as suggested by Heinemann (2020). There, a simulation has been performed demonstrating how the funds would be allocated if those criteria were resorted to. The use of that criterion can be justified by models for fiscal insurance systems that posit that payments are guided by fluctuations in growth. However, it must be stated that it is difficult to imagine an insurance system that does not only insure idiosyncratic risks, but, that makes payments in the case where every insured is hit by the shock. Nevertheless, this principle can be applied to the determination of compensation payments.

In the rest of this note we proceed as follows. In section 2 , we define what we understand by discrimination in this note and we show how the resources of the Covid-19 compensation fund and the damages after compensation are determined when they are distributed according to the relative losses in GDP. Section 3 uses the theoretical results to compute the compensations for the EU 27 and we compare our outcome with that suggested by the Council of the EU. Section 4, finally, summarizes our results and concludes 
the note.

\section{Theoretical background}

The EU has decided to set up a fund in order to compensate the economies for damages resulting from the Covid-19 pandemic. As already mentioned in the previous section there exist several concepts according to which the resources could be distributed to the Member States. One possibility would be to resort to the same relative sacrifice principle (see Greiner and Owusu, 2020). However, that principle would lead to negative compensations for some economies with an overall compensation fund of 337 billion euros which equals 312 billion in 2018 prices. Therefore, we refrain from applying that concept to compute the compensation payments in this note.

Another possibility is to distribute the fund according to the damages incurred by the countries. That could be done either proportionally to the absolute loss of GDP per capita or in accordance to the loss in GDP relative to the level of GDP. Since a focus on the absolute loss of GDP per capita neglects that richer economies can bear higher damages, we resort to the relative loss of GDP as the criterion according to which the resources of the compensation fund are distributed. The fact that richer countries or individuals can suffer higher losses is a principle that has been accepted by a great many economic theorists.

Nevertheless, we should like to point out that other concepts would be feasible, too. However, we argue that all should be such that they only consider damages caused by the Covid-19 pandemic and any criteria not related to that shock lead to an unequal treatment of the damages and, thus, to discrimination. Before we show how the resources are spent when the distribution is proportional to the relative loss in GDP, we give a formal definition of our notion of discrimination in this note.

Definition Discrimination is given if the payments to individual countries are based on criteria such that the relative damages, i.e. losses in GDP relative to GDP, are treated differently in the countries. Negative (positive) discrimination of a country is given when the compensation payments relative to the damages before compensation are lower (higher) than in the case where the distribution is based on a concept that treats the relative 
damages equally.

Next, we want to determine the compensation payments for the countries and the damages after compensation when the distribution is done in accordance to the relative loss of GDP. To do so we consider an economic union consisting of $n$ sovereign states. An asymmetric shock hits the economies of the union causing damages $S_{i}^{v}, i=1, \ldots, n$, in the countries with $S^{v}=\sum_{i=1}^{n} S_{i}^{v}$. Damages are measured by the reduction of the GDP. The union sets up a fund with a total amount of $Z$ that is distributed to the economies where each country receives $Z_{i}, i=1, \ldots, n$, with $Z=\sum_{i=1}^{n} Z_{i}$ according to its loss of GDP relative to GDP before the shock.

We denote by $Y_{i}^{v}$ the GDP in country $i$ before the shock, $i=1, \ldots, n$. All variables are nominal and measured in euro and we have $S_{i}^{v}<Y_{i}^{v}$. Further, we posit that no country receives a compensation that exceeds its damage, i.e. $Z_{i} \leq S_{i}^{v}$ must hold. If the damage in a country falls short of its compensation payment it received following the principle that the resources are distributed proportional to the relative loss of GDP, that economy is fully compensated such that $S_{i}=0$ holds, with $S_{i}$ the damage in country $i$ after compensation, $i=1, \ldots, n$.

The next proposition summarizes our distribution mechanism that is based on the relative loss in GDP.

Proposition Assume that the payments $Z_{i}, i=1, \ldots, n$, are determined according to the losses in GDP relative to GDP before the shock. Then, they are obtained as

$$
Z_{k}=\min \left\{Z\left(\frac{s_{k}^{v}}{\sum_{i=1}^{n} s_{i}^{v}}\right), S_{k}^{v}\right\}, k=1, \ldots, n
$$

with $s_{i}^{v}=S_{i}^{v} / Y_{i}^{v}>0, i=1, \ldots, n$, damages relative to GDP before compensation. The damages after compensation are given by

$$
S_{k}=\max \left\{\left(\frac{s_{k}^{v}}{\sum_{i=1}^{n} s_{i}^{v}}\right)\left(Y_{k}^{v} \sum_{i=1}^{n} s_{i}^{v}-Z\right), 0\right\}, k=1, \ldots, n .
$$

Proof: Obviously, distributing $Z$ according to the relative loss in GDP implies $Z_{k} / Z=$ $s_{k}^{v} / \sum_{i=1}^{n} s_{i}^{v}$ and, thus, $Z_{l} / Z_{m}=s_{l}^{v} / s_{m}^{v}$. Further, $Z_{k} \leq S_{k}^{v}$ and $\sum_{i=1}^{n} Z_{i}^{v}=Z$ must hold. 
Inserting $Z_{k}$ in $S_{k}=S_{k}^{v}-Z_{k} \geq 0$ gives the second expression in the proposition.

In the next section we compute the compensation payments for EU countries when the fund is distributed according to the relative loss of GDP and compare it to the outcome obtained when the EU criteria are resorted to.

\section{The Covid-19 compensation fund}

In this section, we proceed by computing our proposed compensation payments for the 27 EU Member States with reference to the proposition in section two 2. We base our argument on the fact that the only criterion which should be considered when designing a distributive mechanism to compensate the countries is to consider their relative GDP losses as a result of Covid-19. This is because the EU Covid-19 fund was established to compensate countries that have suffered losses resulting from that pandemic. We reiterate that any other compensation mechanism making use of exogenous factors could be deemed discriminatory.

Regarding the data for the quantitative analysis, we used GDP 2019 as a proxy for GDP before Covid-19 and obtained the data from Eurostats website (cf. Eurostat, 2020). Regarding damages or losses in GDP, we used GDP growth contractions for 2020 and 2021 from the European commission autumn forecast (see European Commission, 2020). Since the available growth contractions or expansions are with reference to the previous years, we compute the GDP contraction for 2021 relative to 2019.

Next, we show some descriptive statistics of our data below. Figure 1 provides a graphical view of the damages or losses caused by Covid-19 in 2020 and 2021 as a ratio of 2019 GDP. Spain, Italy, Croatia, Portugal, France and Greece are the countries mostly affected by the pandemic in 2020. We notice that the GDP losses in 2020 exceed that of 2021 for all the countries. This is feasible since countries are expected to recover slowly from the shock caused by the pandemic. Ireland and Lithuania are expected to grow in 2021 relative to their GDP in 2019 as compared to the other Member States. Other smaller economies, such as Denmark, Sweden and Luxembourg, are also expected to experience smaller relative losses in GDP compared to their bigger European counterparts.

Table 1 shows the compensations according to the relative loss in GDP for the EU-27. 
Figure 1: Losses due to the Covid-19 pandemic (as GDP ratios)

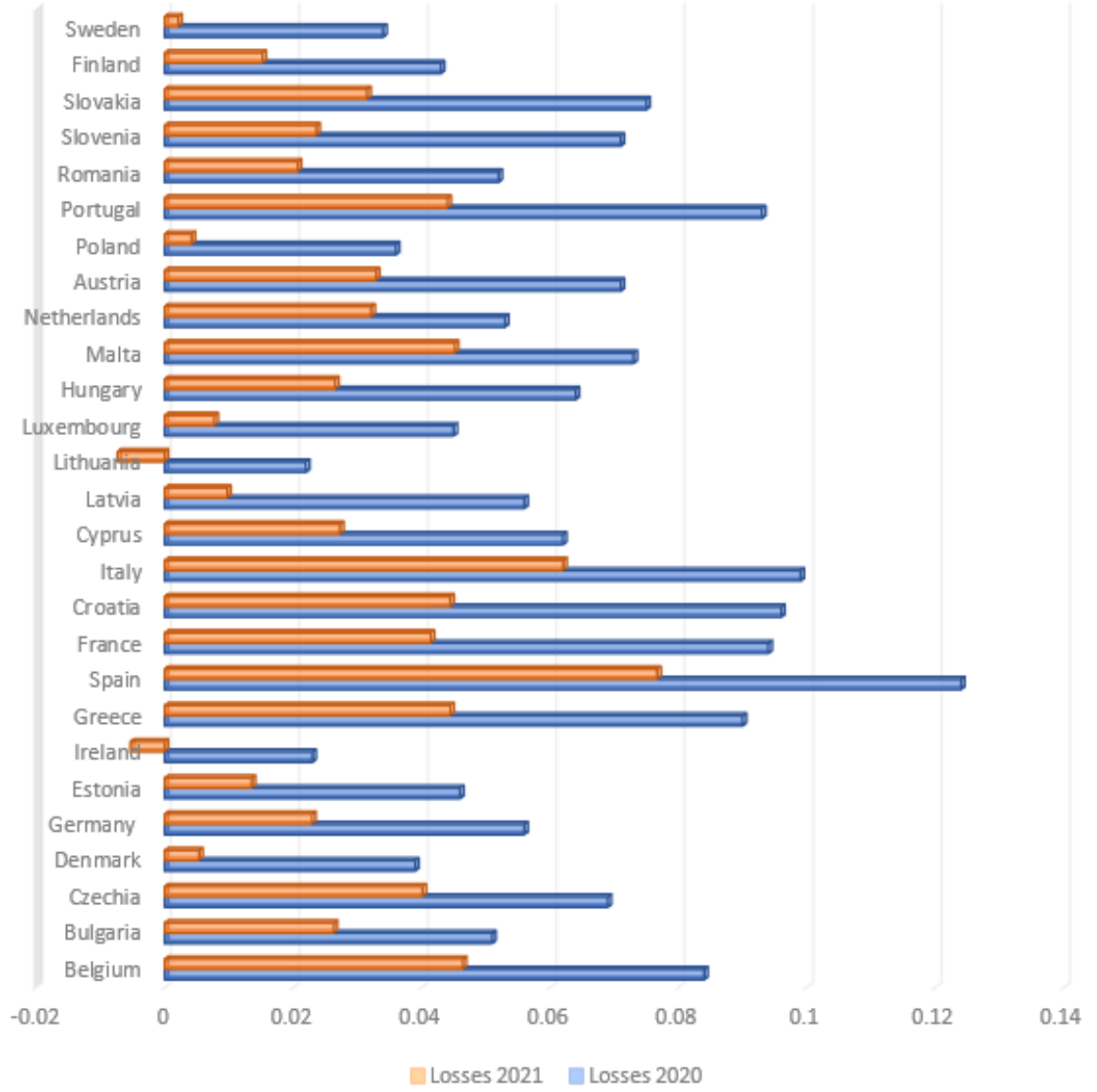

A total compensation amount of 337.969 billion is used for the distribution since this is the total amount used by the Council of the EU in their computation of the financial contribution per EU member state (cf. Council of the EU, 2020, p. 50). The second column in the table shows the 2019 GDP whilst the third column depicts the total loss in GDP before Covid-19 (sum of loss in 2020 and 2021). The fourth column shows compensations calculated according to the relative losses in GDP as a result of Covid-19. Our distribution mechanism ensures that no country is compensated more than its loss in GDP. Therefore, we have computed the compensation such that any excess of compensation over losses for a particular country is redistributed to other countries according to their relative losses in GDP. We do this repeatedly until all countries received at most compensations which are 
equivalent to their losses in GDP and not more. This can be seen in column 5, where we show the ratio of compensation payments to losses in GDP before compensation. It can be observed that 12 out of the $27 \mathrm{EU}$ countries are compensated fully for their losses in GDP since the ratio $\left(Z_{i} / L_{i}^{v}\right)$ is negative 1 for these countries. In other words, losses $\left(L_{i}^{v}\right)$ and compensations $\left(Z_{i}\right)$ are equal for Bulgaria, Estonia, Greece, Croatia, Cyprus, Lithuania, Latvia, Luxembourg, Hungary, Malta, Slovenia and Slovakia. All other countries with a compensation to loss ratio of less than 1, in absolute values, implies that they have not been fully compensated. This results because the total compensation amount of euros 337.969 billion is less than the total loss due to Covid-19 of about euros 1,530.162 billion. We have computed the compensation according to relative losses in GDP judiciously such that no country is compensated beyond its damages and not at the expense of other EU countries.

We turn our attention next to the compensation package proposed by the Council of the European Union (2020, p. 50). There, a table has been provided which depicts the maximum financial contribution per EU member states summing up to 337.969 billion euros. We replicate the compensation for member countries in the third column $\left(Z_{i}^{e u}\right)$ in table 2 below. The EU distribution mechanism as explained in section 1 of this note is a combination of $70 \%$ weight on the product between the unemployment rates, the inverse of GDP per capita and the population of the countries all relative to the EU average for these variables. The remaining 30\% weight is assigned to the product of relative GDP loss between 2020-2019 and 2021-2019, the inverse of GDP per capita and the population relative to the $2019 \mathrm{EU}$ average. Comparing column 3 (losses before compensation) and column 4 (compensations) in table 2 , we notice that some countries will receive more funds that exceed their losses in GDP, notably Bulgaria, Lithuania and Poland. Column 4 depicts the ratio of compensations to losses before compensation and reveal that Lithuania will receive a compensation equivalent to about 300\% of its losses due to Covid-19 and Bulgaria and Poland get more than $100 \%$ of their losses. This is definitely at the expense of other EU economies because the total amount of funds allocated for distribution is not sufficient enough to offset the total loss for all EU Member States.

In order to ascertain the extent of the discrimination due to the EU computation of the financial contribution, we recall the definition in section 2. Negative (positive) discrimination of a country is given when the compensation payments relative to the 
Table 1: Losses before compensation, $L_{i}^{v}=-S_{i}^{v}$ and compensations according to relative losses in GDP, $Z_{i}$.

\begin{tabular}{|c|c|c|c|c|}
\hline Country & GDP 2019 & $L_{i}^{v}$ & $Z_{i}$ & $Z_{i} / L_{i}^{v}$ \\
\hline \hline Belgium & $476,203.300$ & $-62,117.863$ & $24,201.666$ & -0.390 \\
\hline Bulgaria & $61,239.500$ & $-4,735.406$ & $4,735.406$ & -1.000 \\
\hline Czechia & $223,950.300$ & $-24,441.712$ & $20,248.885$ & -0.828 \\
\hline Denmark & $312,747.200$ & $-13,875.030$ & $8,231.171$ & -0.593 \\
\hline Germany & $3,449,050.000$ & $-272,336.988$ & $14,649.685$ & -0.054 \\
\hline Estonia & $28,112.400$ & $-1,674.487$ & $1,674.487$ & -1.000 \\
\hline Ireland & $356,051.200$ & $-6,290.357$ & $3,277.811$ & -0.521 \\
\hline Greece & $183,413.500$ & $-24,669.116$ & $24,669.116$ & -1.000 \\
\hline Spain & $1,244,772.000$ & $-249,820.761$ & $37,235.729$ & -0.149 \\
\hline France & $2,425,708.000$ & $-328,567.000$ & $25,130.815$ & -0.076 \\
\hline Croatia & $54,237.900$ & $-7,618.906$ & $7,618.906$ & -1.000 \\
\hline Italy & $1,789,747.000$ & $-288,254.862$ & $29,881.758$ & -0.104 \\
\hline Cyprus & $22,286.900$ & $-1,990.086$ & $1,990.086$ & -1.000 \\
\hline Latvia & $30,463.300$ & $-2,002.779$ & $2,002.779$ & -1.000 \\
\hline Lithuania & $48,797.400$ & -715.370 & 715.370 & -1.000 \\
\hline Luxembourg & $63,516.300$ & $-3,350.802$ & $3,350.802$ & -1.000 \\
\hline Hungary & $146,061.800$ & $-13,227.357$ & $13,227.357$ & -1.000 \\
\hline Malta & $13,462.400$ & $-1,591.121$ & $1,591.121$ & -1.000 \\
\hline Netherlands & $810,247.000$ & $-69,005.496$ & $15,801.103$ & -0.229 \\
\hline Austria & $397,575.300$ & $-41,312.447$ & $19,278.919$ & -0.467 \\
\hline Poland & $532,329.200$ & $-21,393.246$ & $7,456.200$ & -0.349 \\
\hline Portugal & $213,301.000$ & $-29,226.930$ & $25,422.102$ & -0.870 \\
\hline Romania & $222,997.600$ & $-16,215.493$ & $13,491.217$ & -0.832 \\
\hline Slovenia & $48,392.600$ & $-4,578.956$ & $4,578.956$ & -1.000 \\
\hline Slovakia & $93,865.200$ & $-9,998.990$ & $9,998.990$ & -1.000 \\
\hline Finland & $240,561.000$ & $-14,011.957$ & $10,806.740$ & -0.771 \\
\hline Sweden & $474,468.200$ & $-17,138.740$ & $6,701.823$ & -0.391 \\
\hline
\end{tabular}

Compensation is given by $Z_{k}=\min \left\{Z\left(\frac{s_{k}^{v}}{\sum_{i=1}^{n_{i}^{v}} s_{i}^{v}}\right), S_{k}^{v}\right\}, k=1, \ldots, n$, where $-S_{k}^{v}=L_{k}^{v}$. Absolute numbers in millions of euros.

damages before compensation are lower (higher) than in the case where the distribution is based on a concept that treats the relative damages equally. Hence, we compare the EU compensations against the compensations based on relative GDP losses, placing emphasis 
Table 2: Losses before compensation, $L_{i}^{v}=-S_{i}^{v}$, EU compensations, $Z_{i}^{e u}$, and the difference between compensations according to GDP losses and EU computations, $\Delta=\left(Z_{i}-Z_{i}^{e u}\right) / L_{i}^{v}$.

\begin{tabular}{|c|c|c|c|c|c|}
\hline Countries & GDP 2019 & $L_{i}^{v}$ & $Z_{i}^{\text {eu }}$ & $Z_{i}^{e u} / L_{i}^{v}$ & $\Delta$ \\
\hline Belgium & $476,203.300$ & $-62,117.863$ & $5,925.271$ & -0.095 & -0.295 \\
\hline Bulgaria & $61,239.500$ & $-4,735.406$ & $6,268.706$ & -1.324 & 0.324 \\
\hline Czechia & $223,950.300$ & $-24,441.712$ & $7,071.676$ & -0.289 & -0.539 \\
\hline Denmark & $312,747.200$ & $-13,875.030$ & $1,551.746$ & -0.112 & -0.481 \\
\hline Germany & $3,449,050.000$ & $-272,336.988$ & $25,619.175$ & -0.094 & 0.04 \\
\hline Estonia & $28,112.400$ & $-1,674.487$ & 969.515 & -0.579 & -0.421 \\
\hline Ireland & $356,051.200$ & $-6,290.357$ & 989.186 & -0.157 & -0.364 \\
\hline Greece & $183,413.500$ & $-24,669.116$ & $17,773.895$ & -0.720 & -0.28 \\
\hline Spain & $1,244,772.000$ & $-249,820.761$ & $69,528.050$ & -0.278 & 0.129 \\
\hline France & $2,425,708.000$ & $-328,567.000$ & $39,377.074$ & -0.120 & 0.044 \\
\hline Croatia & $54,237.900$ & $-7,618.906$ & $6,296.831$ & -0.826 & -0.174 \\
\hline Italy & $1,789,747.000$ & $-288,254.862$ & $68,895.833$ & -0.239 & 0.135 \\
\hline Cyprus & $22,286.900$ & $-1,990.086$ & $1,006.170$ & -0.506 & -0.494 \\
\hline Latvia & $30,463.300$ & $-2,002.779$ & $1,963.088$ & -0.980 & -0.02 \\
\hline Lithuania & $48,797.400$ & -715.370 & $2,224.690$ & -3.110 & 2.110 \\
\hline Luxembourg & $63,516.300$ & $-3,350.802$ & 93.526 & -0.028 & -0.972 \\
\hline Hungary & $146,061.800$ & $-13,227.357$ & $7,175.838$ & -0.542 & -0.458 \\
\hline Malta & $13,462.400$ & $-1,591.121$ & 316.474 & -0.199 & -0.801 \\
\hline Netherlands & $810,247.000$ & $-69,005.496$ & $5,962.324$ & -0.086 & -0.143 \\
\hline Austria & $397,575.300$ & $-41,312.447$ & $3,462.169$ & -0.084 & -0.383 \\
\hline Poland & $532,329.200$ & $-21,393.246$ & $23,856.987$ & -1.115 & 0.766 \\
\hline Portugal & $213,301.000$ & $-29,226.930$ & $13,910.387$ & -0.476 & -0.394 \\
\hline Romania & $222,997.600$ & $-16,215.493$ & $14,248.020$ & -0.879 & 0.047 \\
\hline Slovenia & $48,392.600$ & $-4,578.956$ & $1,777.322$ & -0.388 & -0.612 \\
\hline Slovakia & $93,865.200$ & $-9,998.990$ & $6,329.994$ & -0.633 & -0.367 \\
\hline Finland & $240,561.000$ & $-14,011.957$ & $2,085.805$ & -0.149 & -0.622 \\
\hline Sweden & $474,468.200$ & $-17,138.740$ & $3,289.248$ & -0.192 & -0.199 \\
\hline & & & & & \\
\hline & & & & & \\
\hline & & & & \\
\hline
\end{tabular}

Source: Council of the EU (2020), p. 50, own computations. Absolute numbers in millions of euros.

on the ratio of compensations to losses due to Covid-19. In other words, we compare $Z_{i} / L_{i}^{v}$ with $Z_{i}^{e u} / L_{i}^{v}$ from table 1 and table 2 , respectively, and posit that any deviation between the two constitutes discrimination. The results are given in the last column of table 2 and are illustrated in figure 2. 
Figure 2: Ratio of compensation payments to losses before compensation

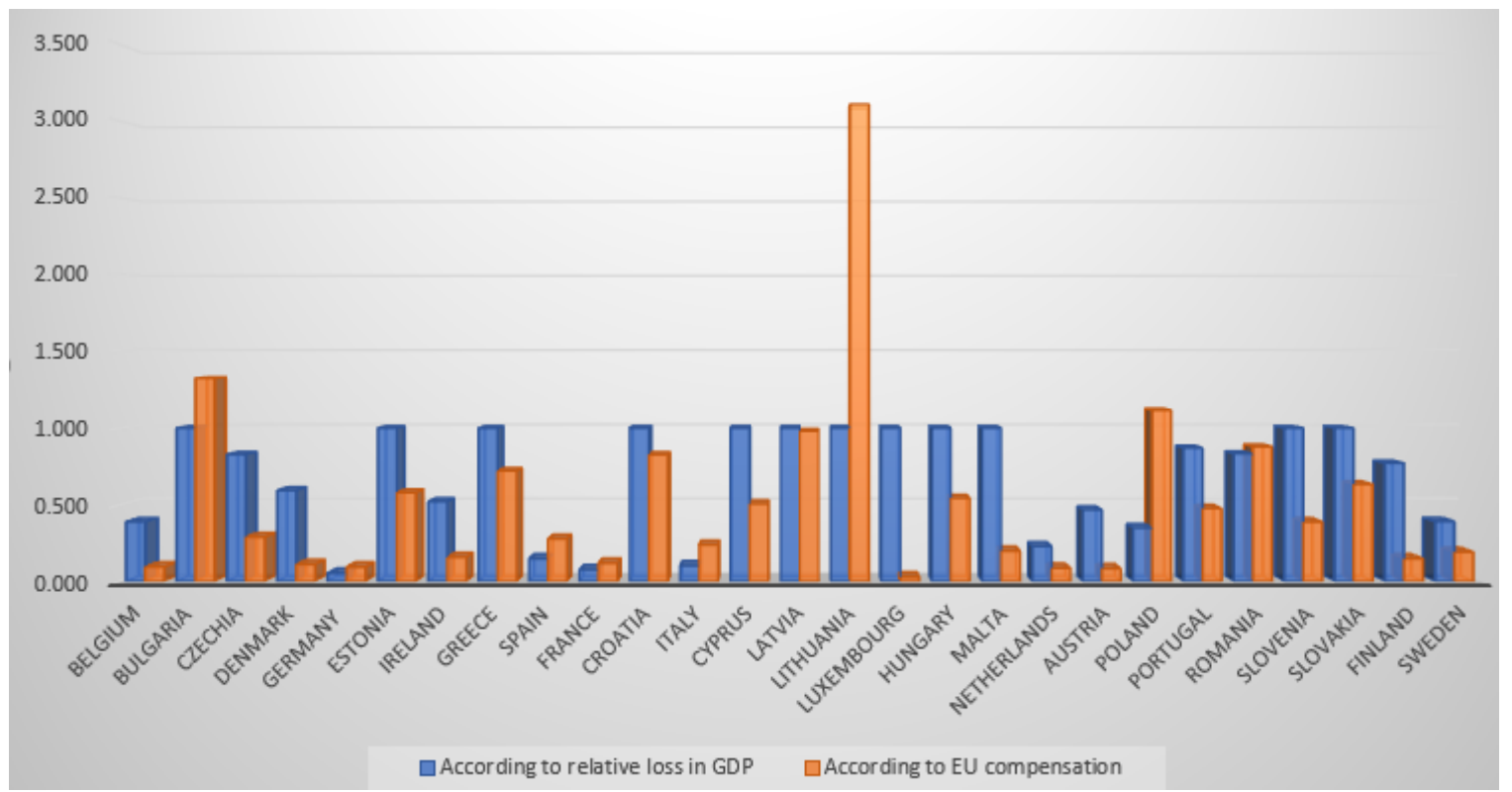

Figure 2 provides a graphical view of the comparison of the compensations relative to losses for the two distribution mechanisms (EU compensations and compensation according to relative losses in GDP). It is important to point out once again that we have used the computation according to the relative loss in GDP as the yardstick to measure discrimination because this distribution is based on the concept that the relative damages are treated equally for all countries. It can be seen from table 2 and from figure 2 that the ratio of compensations to losses according to $\mathrm{EU}$ criteria is greater than the ratio of compensations to losses according to relative GDP losses for some economies. This is the case for Bulgaria, Germany, Spain, France, Italy, Lithuania, Poland and Romania. Hence, we infer that these countries have been positively discriminated because the EU compensations relative to the losses exceed the compensations relative to losses if we consider the computations according to relative GDP losses. Conversely, other countries such as Belgium, Czechia, Denmark, Estonia, Ireland, Greece, Croatia, Cyprus, Latvia, Luxembourg, Hungary, Malta, Netherlands, Austria, Portugal, Slovenia, Slovakia, Finland and Sweden have been negatively discriminated against. This is because the EU compensations relative to the losses are less than the compensations relative to losses if 
we compute them according to relative losses in GDP.

The above results and the discussion provide evidence to suggest that most countries would be negatively discriminated against by the EU distribution of the Covid-19 funds. This is not surprising considering the fact that some of the variables used by the EU for the determination of the compensations such as unemployment from 2015 to 2019 and population are unrelated to the damage caused by the pandemic to EU economies. We, therefore, propose a mechanism that ensures that compensations are based only on losses related to the Covid-19 pandemic and the computations rely on the fact that relative losses are to be treated equally for all countries to avoid any form of discrimination.

\section{Conclusion}

In this note we have shown how the compensation payments of the EU Covid-19 compensation fund are determined when they are distributed in accordance to the relative loss of GDP and we compared the outcome to that proposed by the Council of the EU. We should like to repeat that this is just one concept according to which the distribution can be done and others would be feasible as well. However, each should only focus on the damages caused by that pandemic. Otherwise, losses are treated differently implying (horizontal) inequality and, thus, discrimination.

Our analysis has demonstrated that the financial package proposed by the Council of the EU to compensate countries in the union affected by the Covid-19 pandemic is largely discriminatory. We have shown this by comparing the EU compensations relative to the losses caused by Covid-19 to the situation where the compensations are computed according to losses relative to GDP. Our results demonstrate that 19 out of $27 \mathrm{EU}$ countries have been negatively discriminated against whilst the others have been positively discriminated against. Secondly, distributing the funds according to the criteria suggested by the $\mathrm{EU}$ implies that some countries will receive more compensations than the damages they incurred as a result of the Covid-19 pandemic. This is at the expense of other countries considering that the total amount of funds to be distributed is not large enough to offset the total damage done by Covid-19 to all EU Member States.

The suggested distribution mechanism of the Council of the EU is yet another example of an arbitrary ad hoc behaviour of the EU. The EU is a union of sovereign countries that 
have agreed upon to yield parts of their sovereignty to the EU, but it is neither a federation of states nor a federal state at all. Each country has retained full sovereignty of its fiscal policy, of most of its labour market regulations, its pension system and other regulations with respect to social security. Consequently, it has to assume complete responsibility as regards its public finances. In the euro area this has lead to the no bail-out clause according to which a country must not be liable for another country's debt which rests on the principle of (vertical) equality. Different situations are to be treated differently implying that citizens of different states with different regulations must not be treated in the same way.

\section{References}

Council of the European Union (2020). Proposal for a Regulation of the European Parliament and of the Council establishing a Recovery and Resilience Facility. Interinstitutional File: 2020/0104 (COD), Brussels, 21 December 2020.

European Commission (2020). European commission autumn forecast, Autumn 2020, European Commission, Brussels, doi:10.2765/878338

Eurostat (2020). GDP and main components (output, expenditure and income), Eurostats, Available at https://ec.europa.eu/eurostat/web/main/data/database [Accessed: 15 February 2021].

Greiner, Alfred and Owusu, Benjamin (2020). "How to spend 750 billion euro? Applying sacrifice theory to determine Covid-19 compensations in the EU." Economics Bulletin, Vol. 40, no. 3: 2457-2470.

Heinemann, Friedrich (2020). "Simulating the distributive effects of the Macron-MerkelRecovery fund." ZEW expert brief 20-07, ZEW, Mannheim.

Lenzi, Mary (2008). "Equal Sacrifice Theory". In: Kolb, Robert W. (ed.) Encyclopedia of Business Ethics and Society, SAGE Publications, Thousand Oaks, doi: 10.4135/9781412956260.n296 